\title{
Was the World Prepared for the Coronavirus Pandemic?
}

\author{
Nilson N Mendes Neto, M.D $D^{1,2,3,4^{*}}$ (iD) \\ ${ }^{1}$ Publications Commitee, Pediatric Infectious Diseases Society, USA \\ ${ }^{2}$ Extension Center, University of California, Davis, USA \\ ${ }^{3}$ Executive Council, American Physician Scientists Association, USA \\ ${ }^{4}$ Department of Family Medicine, Onofre Lopes University Hospital, Brazil
}

The most common symptoms of COVID-19 are usually cough, myalgia or fatigue, shortness of breath, and fever [1]. Intestinal symptoms such as diarrhea may occur in up to $25 \%$ of cases. Other symptoms such as hemoptysis and headache have been reported. The clinical course may be worsened when co-morbidities such as cardiovascular disease, hypertension, and diabetes are present [1]. SARS-CoV2 is a virus that has caused a respiratory disease (COVID-19) which was identified in December 2019 in China. Coronaviruses are a large viral family, known since the mid-1960s that cause respiratory infections in humans and animals [2]. Generally, coronavirus infections cause mild to moderate respiratory illnesses, similar to a common cold [3].

The panic caused by COVID-19 stems from uncertainty about the best methods to deal with the situation, in addition to the growing number of fake news released daily. No country in South America has a health system well prepared to deal with this new pandemic. There is still much scope for improvement in health systems around the world and the effects of this unpreparedness are reflected in the data that is released every day. Currently, many countries have used isolation as a method to prevent the rapid spread of the disease, and this fact alone can leave many in a panic.

The current virus has a high spread [4], even greater than in many other pandemics [5]. The importance of adopting social isolation measures is in the fact that it prevents the health system from being burdened with a pathology that, according to WHO [6], is controllable. If there is no effective control over the number of new cases, the health system can become overburdened and other diseases with even greater mortality may be neglected.

On the other hand, the social isolation is causing serious financial impacts and it is directly linked to the degree of sensitivity and economic vulnerability of the countries. The longer the duration of the isolation measures, the greater the economic slowdown will be. Based on other international outbreaks such as SARS, MERS, and Influenza, economic slowdowns can only be reversed after stabilization and control of cases [7]. Countries that were able to adopt isolation measures early today have a better result in controlling the number of cases [8].
Due to the financial crisis caused by the pandemic, many countries have provided financial assistance to overcome problems in the economies and help the population, especially informal workers and small business owners. The private sector does not yet know the magnitude of the problem. But there is a certainty: He will bear a large part of it and he has already started to do so. They expect that the problem will be shared with all sectors, especially those whose institutional duty is to serve society.

But, how can we definitely stop this pandemic? The only answer is a vaccine. There are many expectations about the emergence of vaccines and experimental treatments. However, there is still no evidence from randomized control trials that these treatments may improve outcomes in patients with suspected or confirmed infection. According to Moderna [9], a vaccine produced an immune response in eight volunteers who received two doses of mRNA-1237 on March. The patients created antibodies at levels similar to those seen in infected people recovering from the SARS-CoV2, according to a note released by the biotechnology company. The study provides a signal that the vaccine may provide protection against the virus. However, scientists are still trying to understand the level of antibodies needed to defend the organism and how long this protection should last. To date, there are no approved treatments or vaccines against covid-19 yet. Health organizations predict that it will take 12 to 18 months to develop an effective immunization against the disease [10].

\footnotetext{
*Corresponding author: Nilson N Mendes Neto, M.D., Publications Commitee, Pediatric Infectious Diseases Society, USA; Extension Center, University of California, Davis, USA; Executive Council, American Physician Scientists Association, USA; Department of Family Medicine, Onofre Lopes University Hospital, Brazil
}

Received: May 25, 2020

Accepted: June 01, 2020

Published online: June 03, 2020

Citation: Neto NNM (2020) Was the World Prepared for the Coronavirus Pandemic?. Res Rev Infect Dis 3(1):66-67 
Until then, the economic uncertainties generated by the pandemic will take on greater dimensions as the economic depression deepens. A disease need not be the worst of all time to produce the worst scenario of all time. It is enough to impose additional burdens on health resources beyond the capacity of these resources.

\section{References}

1. Abbasi-Oshaghi E, Mirzaei F, Farahani F, et al. (2020) Diagnosis and treatment of coronavirus disease 2019 (COVID-19): Laboratory, PCR, and chest CT imaging findings. Int J Surg.

2. Yang $P$, Wang $X(2020)$ COVID-19: A new challenge for human beings. Cellular \& Molecular Immunology 17: 555-557.

3. CDC (2020) Common human coronaviruses.
4. (2020) Coronavirus: The first three months as it happened. Nature.

5. Callaway E, Cyranoski D, Mallapaty S, et al. (2020) The coronavirus pandemic in five powerful charts. Nature 579: 482-483.

6. WHO (2020) Coronavirus (COVID-19) events as they happen.

7. OECD (2020) OECD economic outlook, interim report march 2020 - Coronavirus: The world economy at risk.

8. Anderson RM, Heesterbeek H, Klinkenberg D, et al. (2020) How will country-based mitigation measures influence the course of the COVID-19 epidemic? The Lancet 395: 931934.

9. Moderna's work on a COVID-19 vaccine candidate. Moderna.

10. WHO (2020) Immunization in the context of COVID-19 pandemic. 